\title{
In Silico Screening of a Novel Inhibitor of $\beta$-Ketoacyl Acyl Carrier Protein Synthase I
}

\author{
Jee-Young Lee, Ki-Woong Jeong, Ju-Un Lee, Dong-II Kang, ${ }^{\dagger}$ and Yangmee Kim* \\ Department of Bioscience and Biotechnology, Bio/Molecular Informatics Center, Konkuk University, Seoul 143-701, Korea \\ "E-mail:ymkim@konkuk.ac.kr \\ ${ }^{\dagger}$ Department of Chemistry, Konkuk University, Seoul 143-701, Korea \\ Received January 31, 2011, Accepted February 12, 2011
}

\begin{abstract}
$\beta$-Ketoacyl acyl carrier protein synthase I (KAS I) is involved in the elongation of unsaturated fatty acids in bacterial fatty acid synthesis and a therapeutic target of designing novel antibiotics. In this study, we performed receptor-oriented pharmacophore-based in silico screening of $E$. coli KAS I (ecKAS I) with the aim of identifying novel inhibitors. We determined one pharmacophore map and selected 8 compounds as candidates ecKAS I inhibitors. We discovered one antimicrobial compound, YKAe1008, $N$-(3-pyridinyl) hexanamide, displaying minimal inhibitory concentration (MIC) values in the range of $128-256 \mu \mathrm{g} / \mathrm{mL}$ against MRSA and VREF. YKAe1008 was subsequently assessed for binding to ecKAS I using saturation-transfer difference NMR spectroscopy. Further optimization of this compound will be carried out to improve its antimicrobial activity and membrane permeability against bacterial cell membrane.
\end{abstract}

Key Words : FAS, KAS I, In silico Screening, STD-NMR, Antibiotics

\section{Introduction}

Because fatty acids are formed a major component of all cell membranes of bacteria, fatty acid biosynthesis is the attractive target for antimicrobial and antimalarial drug discovery. ${ }^{1,2}$ In bacteria, fatty acid synthesis is controlled by a multifunctional enzyme complex system (fatty acid synthase; FAS) which consists of seven protein domains. Two basic types of FAS architecture exist in nature, designated FAS I and FAS II..$^{3-5}$ FAS II participates in fatty acid biosynthesis in the majority of bacteria and plants. Among the several enzymes of FAS II, three $\beta$-ketoacyl acyl carrier protein synthase (KAS) enzymes, we call it the condensing enzymes, KAS I (FabB), KAS II (FabF), and KAS III (FabH), are excellent targets for the design of novel antibiotics. ${ }^{2,6}$ Pathway of FAS II system is presented in Figure 1(a).

KAS I leads the Claisen condensation reaction to generate short chain fatty acids (C6-C16) and KAS II catalyses elongation of palmitoleic acid (C16:1). ${ }^{2}$ Although KAS I and II involve in the elongation steps in saturated fatty acids synthesis, KAS I is required to elongate an intermediate in unsaturated fatty acid synthesis, whereas KAS II is performed on the final step in the unsaturated pathway. ${ }^{2}$ The initiation condensing enzyme, KAS III, catalyzes the initial condensation of acetyl-CoA with malonyl-ACP and then KAS III is a popular therapeutic target. ${ }^{2,7}$

KAS I is a homodimeric enzyme and it involved in a critical step in the elongation of unsaturated fatty acids. ${ }^{8,9}$ The active site of KAS I contains a His-His-Cys catalytic triad hole, which is conserved in various bacterial KAS I. ${ }^{10}$ There are not many studies for the discovery of inhibitors against KAS I, yet. Since the three-dimensional structure of KAS I is highly conserved in various bacteria, its inhibitors may thus act as potent antibiotics with broad-spectrum activity. Therefore, the inhibition of the elongation of fatty acids by inhibiting KAS I is a powerful target for discovery of novel antibiotics.

In our previous researches, we have successfully discovered the antimicrobial inhibitors of KAS III. ${ }^{11-13}$ Using receptororiented pharmacophore-based in silico screening and automated docking study, we discovered three potent antimicrobial KAS III inhibitors, such as 4-cyclohexyliminomethyl-benzene-1,3-diol (YKAs3003) and two natural products, 3,6-dihydroxyflavone and phloretin. ${ }^{11,13}$ Specially these two natural compounds showed display an excellent antimicrobial activity against $S$. aureus and MRSA. Also we proposed the known antimicrobial flavonoids (Naringenin, eriodictyol, and taxifolin) can be inhibitors of efKAS III by automated docking study. ${ }^{12}$

Based on the techniques developed for discovery of KAS III inhibitors, we performed receptor-oriented pharmacophore-based in silico screening for E. coli KAS I (ecKAS I). Antimicrobial activities of candidate inhibitors against Gramnegative Escherichia coli (E. coli) and Gram-positive Staphylococcus aureus (S. aureus) and Enterococcus faecalis (E. faecalis) as well as methicillin-resistant $S$. aureus (MRSA) and vancomycin-resistant $E$. faecalis (VREF) were measured. Binding of inhibitors to ecKAS III were assessed using saturation transfer difference NMR (STD-NMR) experiment.

\section{Methods}

3D Compound Database. 250,000 synthetic compounds from Specs.net (Kluyverweg, Netherlands) and Maybridge Chemical Company (Tintagel, Cornwall, England) included a database. All compounds were converted to 3D databases with multiple conformers by applying the catDB utility program, as implemented in Catalyst ${ }^{\mathrm{TM}}$ (Accelrys Inc.; San 
Diego, CA). Multiple conformers were generated using the FAST search method, and a maximum 250 conformers was allowed within an energy cut-off range of $20 \mathrm{kcal} / \mathrm{mol}$. Default values of all other parameters were applied. ${ }^{14}$

Receptor-oriented Pharmacophore-based in silico Screening of ecKAS I. Pharmacophores are typically defined by three chemical features, specifically, hydrogen bond donors (HBDs), hydrogen bond acceptors (HBAs) and lipophilicity (Lipo). Active sites of proteins or receptors often present these characteristics, which are combined to establish pharmacophore maps. Pharmacophore maps were determined with the excluded volume for heavy atoms, which is the forbidden area in the active site that defines its shape. An exclusion model was generated for the active site and surrounding receptor regions and heavy atoms in the receptor accounted for the excluded volume. Each receptor atom selected for inclusion in the model was presented as an exclusion point. ${ }^{15-17}$

We defined the active site of ecKAS I, based on the center and radius of the binding substrate in two x-ray structure of ecKAS I complexed with inhibitors. ${ }^{9}$ One pharmacophore map that effectively expressed the binding model of enzyme with inhibitor were determined for searching the compound library. Compounds were further subjected to antimicrobial and binding assays.

Computational studies were performed on a Linux environment using the Cerius ${ }^{2} / \mathrm{SBF}$ 1vmodule (Accelrys Inc.; San Diego, CA) and catSearch utility, as implemented in Catalyst ${ }^{\mathrm{TM}}$ (Accelrys Inc.; San Diego, CA).

MIC Test. The antimicrobial activities of inhibitor candidates were examined using the standard two-fold serial broth dilution method with five bacterial species, including Gramnegative bacteria (E. coli (KCTC 1682) and Gram-positive bacteria (S. aureus (KCTC 1621), E. faecalis (KCTC 2011)), MRSA (CCARM 3114), and VREF (clinically isolated). The three standard bacteria were purchased from the Korean Collection for Type Cultures (KCTC) (Taejon, Korea). ${ }^{18,19}$ The clinical isolate of MRSA and VREF was supplied by Culture Collection of Antimicrobial Resistant Microbes (CCARM) (Seoul, Korea).

The bacterial suspension was adjusted to 0.5 McFarland standard prepared from a single colony on an agar plate incubated for 18-24 h, and diluted 10-fold in Mueller Hinton broth. A $20 \mu \mathrm{L}$ aliquot of the diluted cell suspension $\left(1 \times 10^{6}\right.$ colony forming units) was used to inoculate each well of a 96-well plate containing $100 \mu \mathrm{L}$ of the same medium with the indicated concentrations of candidate inhibitors. Plates were incubated at $37^{\circ} \mathrm{C}$ for $20 \mathrm{~h}$. MIC was defined as the lowest concentration of antibiotic leading to complete inhibition of visible growth in relation to an antibiotic-free control well. Experiments were replicated at least three times to verify methodology reproducibility using the above conditions.

Expression and Purification of ecKAS I. The $f a b B$ gene encoding KAS I was amplified from E. coli K-12 genomic DNA. The sense primer is 5'-catatgaaacgtgcagtgattact-3', and antisense primer is $5^{\prime}$-ctcgagttaatctttcagcttgc- $3{ }^{\prime}$. At the $5^{\prime}$ end of each primer, a restriction site (NdeI for the sense primer and XhoI for the antisense primer) was attached to facilitate cloning. PCR was performed under the following conditions: 35 cycles of denaturation for $1 \mathrm{~min}$ at $94{ }^{\circ} \mathrm{C}$, annealing for $1 \mathrm{~min}$ at $55^{\circ} \mathrm{C}$, and extension for $1 \mathrm{~min}$ at 72 ${ }^{\circ} \mathrm{C}$. The resulting product was sequenced and cloned between the NdeI and XhoI sites of pET-15b vector. The ligation mixture was transformed into $E$. coli $\mathrm{DH} 5 \alpha$ competent cells. The pET-15b/ecKAS I plasmid was transformed into the expression host, E. coli BL21 (DE3). Transformed cells were grown on Luria-Bertani (LB) agar plates containing 50 $\mathrm{mg} / \mathrm{L}$ ampicillin and grown overnight in a $37{ }^{\circ} \mathrm{C}$ shaking incubator. Fully grown culture $(10 \mathrm{~mL})$ was mixed with 1 liter of fresh AMP-LB, and grown at $37{ }^{\circ} \mathrm{C}$ until an optical density at $600 \mathrm{~nm}$ of 0.5 . The culture was induced with 1 $\mathrm{mM}$ IPTG and grown for 5 more hours at $18{ }^{\circ} \mathrm{C}$. Cells were harvested, and the pellet stored at $-80{ }^{\circ} \mathrm{C}$.

All lysis and purification procedures were performed at $4{ }^{\circ} \mathrm{C}$. The frozen pellet was resuspended and lysed by ultrasonication in buffer A containing $50 \mathrm{mM}$ Tris- $\mathrm{HCl}$ and 300 $\mathrm{mM} \mathrm{NaCl}$ at $\mathrm{pH}$ 8.0. The cell lysate was centrifuged and suffered denaturation step in $8 \mathrm{M}$ urea. The supernatant loaded onto a HiTrap chelating column (GE) pre-equilibrated with buffer A. The column was washed with buffer A, and the bound material eluted with a linear gradient from 0 to $300 \mathrm{mM}$ imidazole. SDS-PAGE was applied to identify the ecKAS I-containing fraction at each stage of purification and suffered refolding step with buffer A which added $2 \mathrm{mM}$ DTT.

Binding Assay using STD-NMR. STD-NMR experiments were performed at $298 \mathrm{~K}$. The protein was saturated onresonance at $-1.0 \mathrm{ppm}$ and off-resonance at $40 \mathrm{ppm}$, with a cascade of 40 selective Gaussian-shaped pulses of $50 \mathrm{~ms}$ duration and $100 \mu$ s delay between each pulse in all STDNMR experiments. ${ }^{20,21}$ The total duration of the saturation time was set to $2 \mathrm{~s}$. For STD-NMR experiments, $10 \mu \mathrm{M}$ recombinant ecKAS I in $50 \mathrm{mM}$ Tris- $\mathrm{HCl}, 300 \mathrm{mM} \mathrm{NaCl}$, $\mathrm{pH}$ 8.0, and candidate inhibitors were mixed at a protein: ligand ratio of 1:100. In total, 1024 scans for each experiment were acquired, and a WATERGATE sequence used to suppress the water signal. A spin-lock filter $(5 \mathrm{kHz}$ strength and $10 \mathrm{~ms}$ duration) was applied to suppress the protein background. All NMR spectra were recorded on Varian Unity Plus $500 \mathrm{MHz}$ and Bruker Avance $500 \mathrm{MHz}$ NMR spectrometers at KBSI.

\section{Results and Discussion}

Two famous antibiotics, Thiolactomycin (TLM) and Cerulenin (CER) shown in Figure 1 are the known inhibitors of KAS. ${ }^{9}$ 3D structures of ecKAS I and the complex structures of TLM and CER have been identified by means of X-ray crystallography (1FJ4.pdb and 1FJ8.pdb), respectively ${ }^{9}$ To define the proper interactions between inhibitors and ecKAS I, we superimposed these two x-ray structures. As shown in Figure 2(b), TLM and CER form a common hydrogen bonding interaction with side chain of H333 and the rest region does not overlapped. H333 is one of the 
(a)

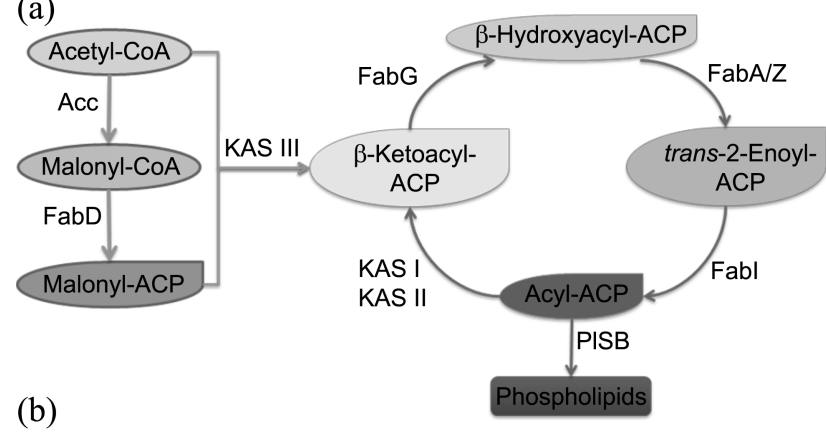<smiles>C=C/C(C)=C/C1SC(=O)C(C)=C1O</smiles>

Thiolactomycin (TLM)<smiles>C/C=C/C/C=C/CCC(=O)C1O[C@@H]1C(N)=O</smiles>

Cerulenin (CER)

Figure 1. Fatty acid biosynthesis and known KAS III inhibitors. (a) Pathway of Fatty Acid Synthesis Type II in E. coli (Acc, acetylCoA carboxylase; FabD, ACP transacylase; FabG, $\beta$-ketoacyl ACP reductase; FabA/Z, $\beta$-ketoacyl ACP dehydratases; FabI, enoyl reductase; PlsB, sn-glycerol-3-phosphate acyltransferase). (b) 2D Structures of known inhibitors, TLM and CER.

histidine residues which consists of triad hole at the active site of KAS I. TLM form a hydrogen bonding with H333 and a hydrophobic interaction of Phe229 and Thr300 with ecKAS I. CER forms two hydrogen bonding interactions with H333 and backbone amide hydrogen of G391 and a hydrophobic interaction with M197, F229, and F231. Because the interaction of TLM-ecKAS I is insufficient, we determined one pharmacophore map on the basis of interaction model between CER and ecKAS I.

As shown in Figure 2(c), the determined pharmacophore map consists of two hydrogen bonding acceptors (HBA1 and HBA2) and one hydrophobic interaction (Lipo1). HBA1 is depicted the interaction with $\mathrm{H} 333$ and HBA2 represented the hydrogen bond with G391. A multiple conformer database which included 250,000 synthetic compounds is constructed and searched with a determined pharmacophore map. We selected the initial 50 hit from highly top ranked of ligand score (LigScore) and finally choose 8 candidates by visual inspections. ${ }^{22,23}$ The $2 \mathrm{D}$ structures of 8 candidates are represented in Figure 3.

The antimicrobial activities of inhibitor candidates were estimated using the standard two-fold serial broth dilution method with four gram-positive bacteria species: $S$. aureus, E. faecalis, MRSA, and VREF as well as one gram-negative bacteria E. coli. As listed in Table 1, among 8 candidates, one compound, YKAe1008, showed antibacterial activities against four gram-positive bacteria values in the range of $128-256 \mu \mathrm{g} / \mathrm{mL}$. TLM also showed similar antibacterial activities to our inhibitor. YKAe1008 exhibited slightly higher antibacterial activities against $S$. aureus and MRSA than Enterococcus strains. Unfortunately, YKAe1008 failed to show antimicrobial activity against $E$. coli and it may be due to difficulty in penetrating the bacterial cell wall against gram-negative bacteria. (a)

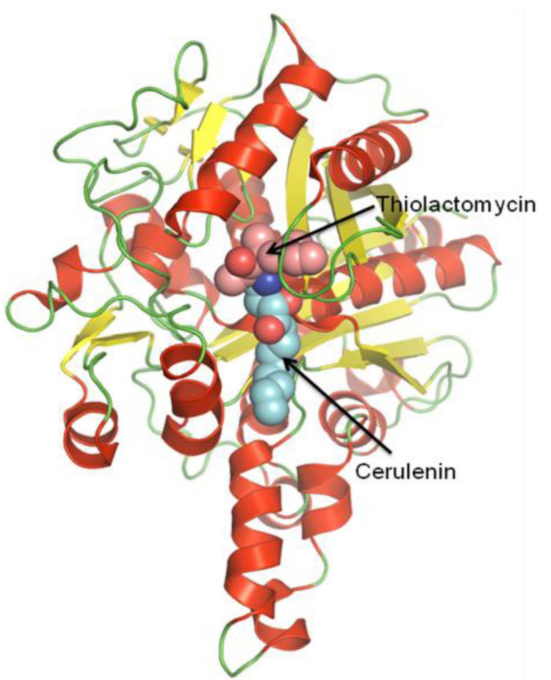

(b)

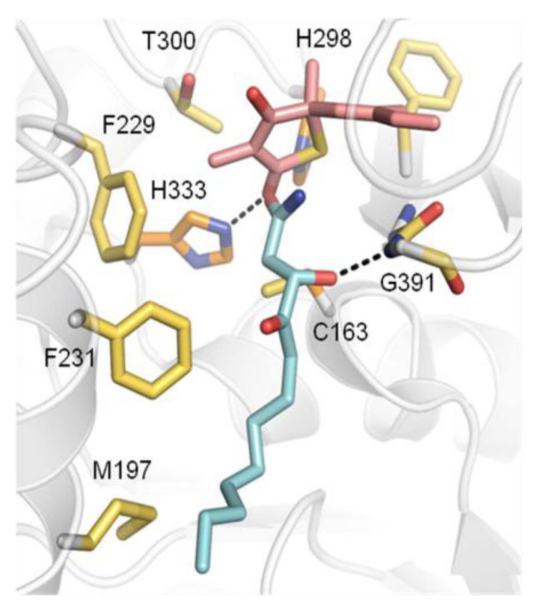

(c)

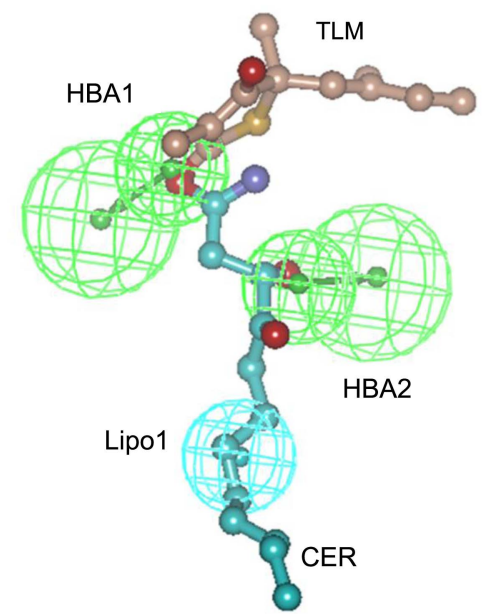

Figure 2. Comparative view of binding models of ecKAS I and its known inhibitors. (a) 3D structure of ecKAS I with inhibitors. (b) Superimposed interaction model of two x-ray complex structure of TLM-ecKAS I (1FJ4.pdb) and CER-ecKAS I (1FJ8.pdb). TLM is depicted in pitch and CER is depicted in cyan. (c) Pharmacophore map determined using receptor-oriented pharmacophore-based in silico screening.

Previously, we have been confronted with the cell permeability problem of designed KAS III inhibitors. ${ }^{11,13}$ We 
<smiles>Cc1cccc(/C=N/NC(=O)C(C)Nc2ccccc2C)n1</smiles>

YKAe1001<smiles>CCCCCCNC(=O)C1CCCCC1C(=O)O</smiles>

YKAe1004<smiles>C=CCN1C(=O)S/C(=C\c2ccc(OC(C)C)cc2)C1=O</smiles>

YKAe1002<smiles>C=C(CS(=O)(=O)c1ccc(C)cc1)C(N)=O</smiles><smiles>CCOCCN1CCN(C(=O)CN2CCCC2=O)CC1</smiles>

YKAe1003<smiles>CC(O/N=C/c1cccc([N+](=O)[O-])c1)C(=O)O</smiles>

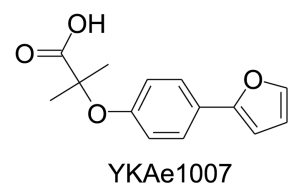<smiles>CCCCCC(=O)Nc1cccnc1</smiles>

Figure 3. 2D Structures of 8 selected compounds hit by pharmacophore map.

Table 1. MIC $(\mu \mathrm{g} / \mathrm{mL})$ values of 8 compounds and TLM against E. coli, S. aureus, E. faecalis, MRSA, and VREF

\begin{tabular}{lccccc}
\hline \multirow{2}{*}{ Compound } & \multicolumn{5}{c}{ MIC $(\mu \mathrm{g} / \mathrm{mL})$} \\
\cline { 2 - 6 } & E. coli & S. aureus & E. faecalis & MRSA & VREF \\
\hline TLM & 128 & 256 & 256 & 128 & 128 \\
YKAe1001 & $>256$ & $>256$ & $>256$ & $>256$ & $>256$ \\
YKAe1002 & $>256$ & $>256$ & $>256$ & $>256$ & $>256$ \\
YKAe1003 & $>256$ & $>256$ & $>256$ & $>256$ & $>256$ \\
YKAe1004 & $>256$ & $>256$ & $>256$ & $>256$ & $>256$ \\
YKAe1005 & $>256$ & $>256$ & $>256$ & $>256$ & $>256$ \\
YKAe1006 & $>256$ & $>256$ & $>256$ & $>256$ & $>256$ \\
YKAe1007 & $>256$ & $>256$ & $>256$ & $>256$ & $>256$ \\
YKAe1008 & $>256$ & 128 & 256 & 128 & 256 \\
\hline
\end{tabular}

solved the problem by calculation of the chemical properties to estimate the cell permeability, such as $\log \mathrm{P}$ and polar surface area (PSA). LogP is the partition coefficient the ratio of water and octanol as a factor of the lipophilicity of molecules $^{24,25}$ and PSA is defined as the surface sum over all polar atom. ${ }^{26}$ These two properties are commonly used for the prediction of cell permeability. ${ }^{27}$ Therefore, further optimization of YKAe1008 is required to improve its cell permeability and antimicrobial activity against various bacteria strain including gram-negative species. The predicted LogP and PSA of YKAe1008 is 2.03 and 41.99, respectively.

Binding of candidate inhibitor, YKAe1008 was characterized using saturation-transfer difference NMR (STDNMR) spectroscopy. Figure 4(a) is the ${ }^{1} \mathrm{H}$ NMR spectra of free YKAe1008 and representative STD-NMR spectra of ecKAS I bound to YKAe1008 $(1 \mathrm{mM})$ is shown in Figure 4(b). The proton signals in STD-NMR spectra are caused by magnetization transfer from the protein to ligand, providing direct evidence of protein-ligand interactions. Protons of the ligand in closest contact with protein are more affected than remote protons, and yield the most intense signals. STD-

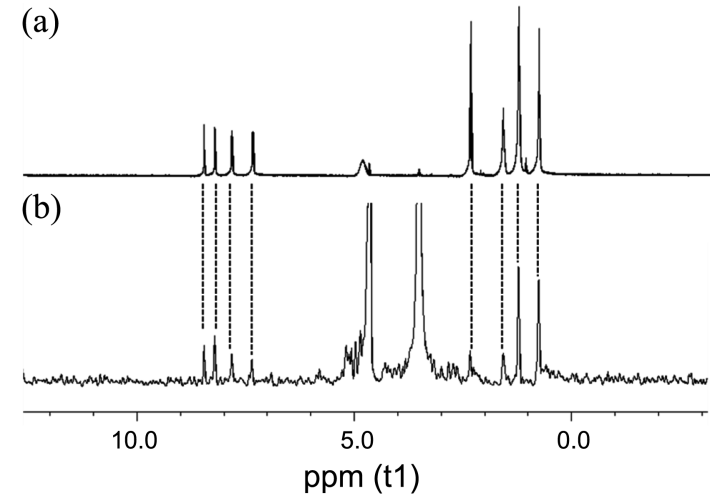

Figure 4. STD-NMR spectra of YKAe1008 showing its effective binding to ecKAS I. Protons of YKAe1008 with magnetization transferred from protein are depicted by dashed lines. (a) 1D spectrum of YKAe1008 in $\mathrm{D}_{2} \mathrm{O}$. (b) STD-NMR spectrum of YKAe1008 with ecKAS I.

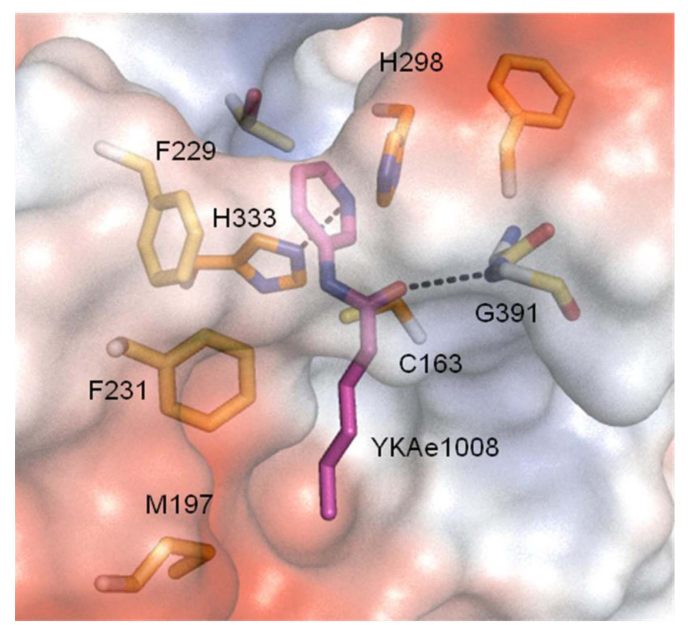

Figure 5. Binding model of ecKAS I and YKAe1008. Hydrogen bondings are denoted by black dashed lines. 
NMR spectra clearly showed that YKAe1008 binds to ecKAS I and we can suggest that YKAe1008 can be potent inhibitors of KAS I.

The chemical name of YKAe1008 is $N$-(3-pyridinyl)hexanamide. As shown in the binding model of YKAe1008 and ecKAS I (Fig. 5), the nitrogen atom of pyridinyl ring formed a hydrogen bond with side chain of H333 and the carbonyl oxygen of hexanamide participated in hydrogen bonding interaction with backbone amide hydrogen of G391. The hexan chain formed a hydrophobic interaction with several residues, such as M197, F229, and F231 as mentioned before. These two hydrogen bond interactions can be contributed to the binding affinity of YKAe1008 to ecKAS I and the hydrophobic interaction can be important for biological activity of compound.

In this study, we successfully designed a novel antimicrobial inhibitor of KAS I. The further research will be focused on the optimization of YKAe1008 to improve its antimicrobial activity and membrane permeability against gram-negative bacteria.

Acknowledgments. This work was supported by National Research Foundation of Korea (NRF) funded by the Ministry of Education, Science and Technology (2009-0076064) and by the Priority Research Centers Program through the National Research Foundation of Korea (NRF) funded by the Ministry of Education, Science and Technology (20090093824). Jeong, K.-W. was supported, in part, by the second BK21 (MOE).

\section{References}

1. Campbell, J. W.; Cronan, J. E., Jr. Annu. Rev. Microbiol. 2001, 55, 305.

2. Khandekar, S. S.; Daines, R. A.; Lonsdale, J. T. Curr. Protein Pept. Sci. 2003, 4, 21.

3. Lu, Y. J.; Zhang, Y. M.; Rock, C. O. Biochem. Cell Biol. 2004, 82,
145 .

4. Marrakchi, H.; Zhang,Y. M.; Rock, C. O. Biochem. Soc. Trans. 2002, 30, 1050 .

5. White, S. W.; Zheng, J.; Zhang, Y. M.; Rock, C. O. Annu. Rev. Biochem. 2005, 74, 791.

6. Heath, R. J.; Rock, C. O. J. Biol. Chem. 1996, 3, 10996.

7. Heath, R. J.; Rock, C. O. Nat. Prod. Rep. 2002, 19, 581.

8. Olsen, J. G.; Kadziola, A.; von Wettstein-Knowles, P.; SiggaardAndersen, M.; Larsen, S. Structure 2001, 9, 233.

9. Price, A. C.; Choi, K. H.; Heath, R. J.; Li, Z.; White, S. W.; Rock, C. O. J. Biol. Chem. 2001, 276, 6551.

10. von Wettstein-Knowles, P.; Olsen, J. G.; McGuire, K. A.; Henriksen, A. FEBS J. 2006, 273, 695

11. Lee, J. Y.; Jeong, K. W.; Shin, S.; Lee, J. U.; Kim, Y. Bioorg. Med. Chem. 2009, 17, 5408.

12. Jeong, K. W.; Lee, J. Y.; Kang, D. I.; Lee, J. U.; Shin, S. Y.; Kim, Y. J. Nat. Prod. 2009, 72, 719.

13. Lee, J. Y.; Jeong, K. W.; Lee, J. U.; Kang, D. I.; Kim, Y. Bioorg. Med. Chem. 2009, 17, 1506.

14. Murrall, N. W.; Davies, E. K. J. Chem. Inf. Comput. Sci. 1990, 30, 312.

15. Hoffrén, A. M.; Murray, C. M.; Hoffmann, R. D. Curr. Pharm. Des. 2001, 7, 547 .

16. Kirchhoff, P. D.; Brown, R.; Kahn, S.; Waldman, M.; Venkatachalam, C. M. J. Comp. Chem. 2001, 22, 993.

17. Fisher, L. S.; Güner, O. F. J. Braz. Chem. Soc. 2002, 13, 777.

18. MacLowry, J. D.; Jaqua, M. J.; Selepak, S. T. Appl. Microbiol. $1970,20,46$.

19. Smaill, F. Can. J. Gastroenterol. 2000, 14, 871.

20. Macnaughtan, M. A.; Kamar, M.; Alvarez-Manilla, G.; Venot, A.; Glushka, J.; Pierce, J. M.; Prestegard, J. H. J. Mol. Biol. 2007, $366,1266$.

21. Mayer, M.; Meyer, B. J. Am. Chem. Soc. 2001, 123, 6108.

22. Venkatachalam, C. M.; Jiang, X.; Oldfield, T.; Waldman, M. $J$ Mol. Graph. Model. 2003, 21, 289.

23. Aparna, V.; Rambabu, G.; Panigrahi, S. K.; Sarma, J. A.; Desiraju, G. R. J. Chem. Inf. Model. 2005, 45, 725.

24. Veber, D. F.; Johnson, S. R.; Cheng, H. Y.; Smith, B. R.; Ward, K. W.; Kopple, K. D. J. Med. Chem. 2002, 45, 2615.

25. Jensen, B. F.; Refsgaardb, H. H. F.; Broc, R.; Brockhoff, P. B. QSAR Comb. Sci. 2005, 24, 449.

26. Ertl, P.; Rohde, B.; Selzer, P. J. Med. Chem. 2000, 43, 3714.

27. Irwin, J. J.; Shoichet, B. K. J. Chem. Inf. Model. 2005, 45, 177. 